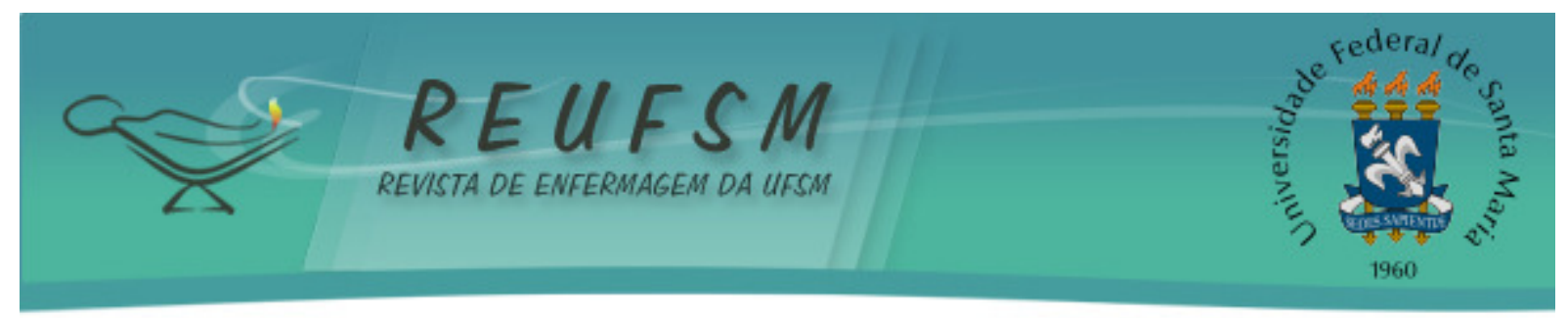

ARTIGO ORIGINAL

\title{
OFICINAS TEMÁTICAS COMO POTENCIALIZADORAS DO CUIDADO A IDOSOS HOSPITALIZADOS ${ }^{1}$
}

THEMATIC WORKSHOPS AS POTENTIATING OF CARE TO ELDERLY IN HOSPITAL TALLERES TEMÁTICOS COMO POTENCIALIZADORES DEL CUIDADO A LOS ANCIANOS HOSPITALIZADOS

\author{
Juliane Elis Both ${ }^{2}$ \\ Marinês Tambara Leite ${ }^{3}$ \\ Leila Mariza Hildebrandt ${ }^{4}$ \\ Ana Maria Massariol ${ }^{5}$ \\ Margrid Beuter ${ }^{6}$ \\ Miriam da Silveira Perrando ${ }^{7}$
}

Doi: $10.5902 / 2179769211009$

RESUMO: Objetivo: analisar as contribuições de oficinas temáticas para o cuidado de idosos hospitalizados, desenvolvidas junto a profissionais de enfermagem. Método: caracteriza-se como um estudo qualitativo e descritivo, que utiliza como referencial teórico-metodológico a pesquisa convergente-assistencial. Os sujeitos do estudo são profissionais de enfermagem de uma unidade de clínica médica, de um hospital do noroeste do estado do Rio Grande do Sul. Resultados: por meio das práticas educativas com os profissionais foi possível unir o saber e o fazer, contribuindo de modo positivo na práxis do cuidado ao idoso hospitalizado. Considerações Finais: as práticas educativas consistem de uma estratégia para qualificar o cuidado ao idoso hospitalizado.

Descritores: Enfermagem; Educação em saúde; Idoso; Assistência à saúde.

Aim: to analyze the contributions of thematic workshopsto care for hospitalized elderly, developed with nursing professionals. Method: it is a qualitative and descriptive research that has the convergent-assistance research as theoretical and methodological reference. The subjects are professionals of nursing of a medical clinic unity of a hospital located in northwest of Rio Grande do Sul. Results: through the educative practices with the professionals, it was possible to connect the to know and do, interfering positively in the praxis of care to hospitalized elderly. Final Considerations: the educational practice consists

\footnotetext{
${ }^{1}$ Artigo produzido a partir da Pesquisa "Prática Educativa como um caminho para Qualificar o cuidado ao idoso Hospitalizado", vinculado ao Trabalho de Conclusão de Curso, para a obtenção do Grau de Bacharel em Enfermagem da Universidade Federal de Santa Maria, Campus Palmeira das Missões.

${ }^{2}$ Enfermeira. Mestranda em Enfermagem pelo Programa de Pós Graduação em Enfermagem da Universidade Federal de Santa Maria - Mestrado em Enfermagem- (PPGEnf). Membro do Grupo de Pesquisa Cuidado, Saúde e Enfermagem. Email: julianeelisboth@hotmail.com

3 Orientadora. Enfermeira, Dra. em Gerontologia Biomédica, docente da UFSM/Campus Palmeira das Missões. Tutora do Grupo PET Enfermagem UFSM/Campus Palmeira das Missões. E-mail: tambaraleite@yahoo.com.br.

${ }^{4}$ Co-Orientadora. Enfermeira. Mestre em Enfermagem Psiquiátrica, docente da UFSM/Campus Palmeira das Missões. E-mail: leilahildebrandt@yahoo.com.br

${ }^{5}$ Co-autora. Acadêmica de Enfermagem da Universidade Federal de Santa Maria, Campus Palmeira das Missões. Bolsista do Programa de Educação Tutorial (PET) Enfermagem UFSM/Campus Palmeira das Missões.

${ }^{6}$ Co-Autora. Enfermeira, Dra. em Enfermagem. Professora Adjunta do Departamento de Enfermagem e do PPGEnf - Curso de Mestrado da Universidade Federal de Santa Maria - UFSM/RS. Membro do Grupo de Pesquisa Cuidado, Saúde e Enfermagem. E-mail: margridbeuter@gmail.com

${ }^{7}$ Co-Autora. Enfermeira, Mestranda em Enfermagem pelo Programa de Pós Graduação em Enfermagem da Universidade Federal de Santa. Membro do Grupo de Pesquisa Cuidado, Saúde e Enfermagem. Email: mperrando@hotmail.com.
} 


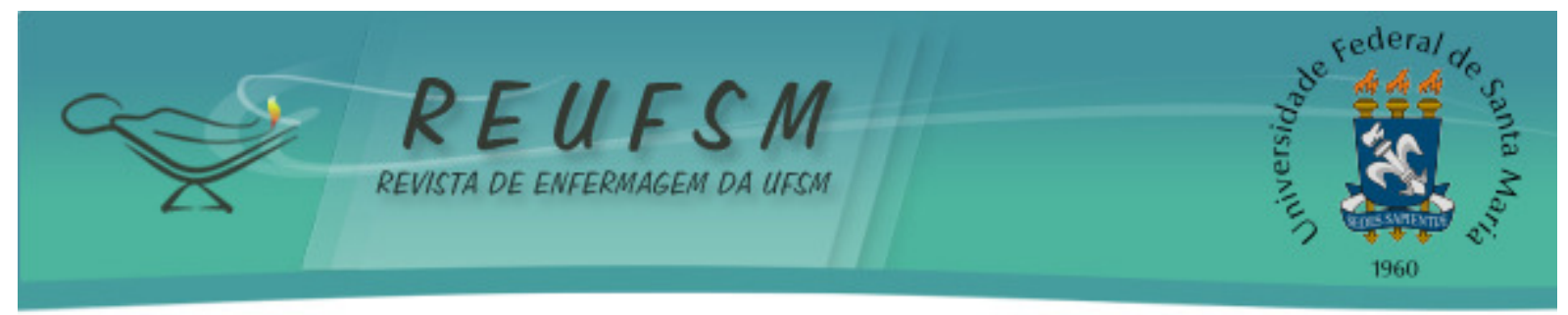

of a strategy to qualify the care with hospitalized elderly.

Descriptors: Nursing; Health education; Aged; Delivery of health care.

RESUMEN: Objetivo: analizar las contribuciones de los talleres temáticos para el cuidado de ancianos hospitalizados, desarrollado con los profesionales de enfermería. Método: se trata de un estudio cualitativo y descriptivo, que utiliza como referencial teóricometodológico la investigación convergente-asistencial. Los sujetos del estudio son profesionales de enfermería de una unidad de clínica médica, de un hospital del noroeste del Estado del Rio Grande do Sul. Resultados: acerca de las prácticas educativas con los profesionales fue posible unir el saber y el hacer, contribuyendo de modo positivo en la praxis del cuidado al anciano hospitalizado. Consideraciones finales: las prácticas educativas consisten de una estrategia para calificar el cuidado al mayor hospitalizado.

Descriptores: Enfermería; Educación en salud; Anciano; Prestación de atención de salud.

\section{INTRODUÇÃO}

O número de idosos vem crescendo em todo o mundo como consequência, em especial, da diminuição das taxas de natalidade e do aumento da expectativa de vida. 0 processo de transição demográfica ocorre em decorrência do envelhecimento populacional, sendo resultado do desequilíbrio entre as taxas de natalidade e de mortalidade e do aumento da expectativa de vida. ${ }^{1}$ Vale destacar que no Brasil, de acordo com a Lei $n^{\circ} 10.741 / 2003$, em seu art. $1^{\circ}$, idoso é toda a pessoa com 60 anos ou mais de idade. ${ }^{2}$

Com o avançar da idade há uma tendência de aumentar os agravos à saúde, favorecendo para a maior ocorrência de doenças, tanto de caráter agudo como crônico. Salienta-se que a hospitalização é comum para a população idosa quando esta vivencia um processo de adoecimento, particularmente nas situações de agudização. Assim, adoecer é um fato frequente entre os idosos, que necessitam ser acompanhados, com vistas a controlar a progressão da doença e favorecer a prevenção de complicações e agravamentos. Neste sentido, diante do perfil de morbimortalidade, que comumente os idosos apresentam, há a necessidade de atenção especial dos serviços de saúde. ${ }^{3} 0$ controle das doenças deve estar estritamente vinculado aos aspectos relativos à prevenção de incapacidades, visando à manutenção da capacidade funcional do idoso, uma vez que as doenças podem interferir e resultar em danos. ${ }^{4}$

Especificamente em relação à hospitalização, esta representa, com frequência, uma situação amedrontadora, estressante e de sofrimento para o indivíduo que a vivencia. ${ }^{5}$ Quando se trata de uma pessoa idosa que necessita de internação hospitalar, deseja-se que ela seja de curta duração e que o idoso e sua família possam ter orientações para dar continuidade ao cuidado no domicílio. Isto porque a hospitalização favorece o agravamento das comorbidades requerendo cuidados especializados. Para tanto, ao idoso deve ser dada atenção para suas necessidades biopsicossociais, realizando avaliação multidimensional gerontogeriátrica, identificando os aspectos físicos, funcionais, mentais e sociais. ${ }^{6}$

Diante das singularidades que os idosos apresentam se entende que, para atender essa demanda, os serviços de saúde necessitam manter um quadro de profissionais que, para além da sua formação, tenham conhecimentos e habilidades relativos ao envelhecimento humano e, ainda, que possam ter acesso a atualizações e capacitações constantes. Entre os profissionais de saúde, está a equipe de enfermagem, a qual é responsável por dispensar o cuidado voltado às necessidades da pessoa idosa e fornecer orientações para ela e sua família.

Destaca-se que, em relação ao cuidado de idosos, este é um paciente que possui alterações biológicas, psíquicas, sociais e espirituais próprias da idade. Particularmente, as modificações biológicas favorecem o surgimento de doenças crônicas, o rápido declínio do 


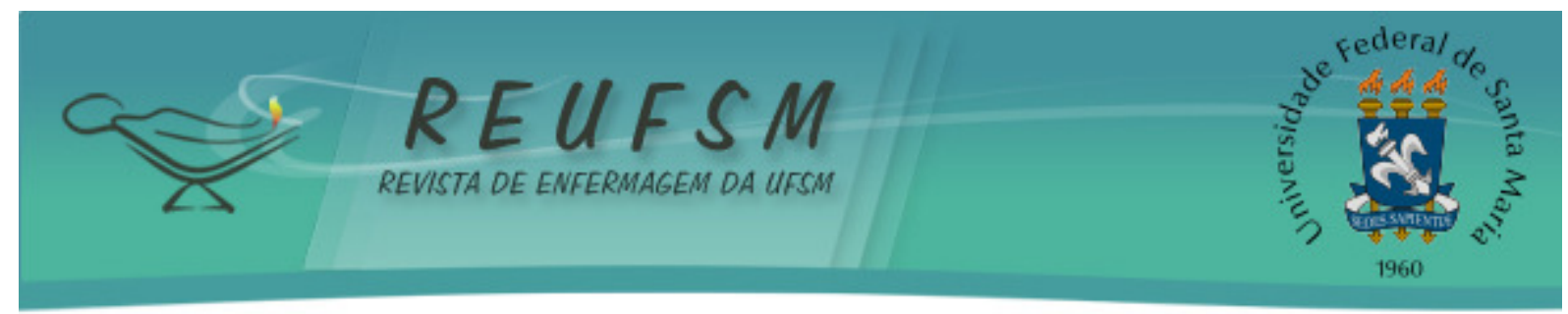

estado geral, as interações medicamentosas, o risco de iatrogenias e a presença de déficits sensoriais e cognitivos, os quais influenciam no cuidado e não devem ser ignorados. ${ }^{7}$

Desse modo, entende-se que buscar a qualificação para o cuidado à pessoa idosa é fundamental para que a enfermagem possa prestar assistência qualificada a este contingente populacional. Os profissionais, além de prestarem assistência integral, não devem manter estigmas e pré-conceitos em relação ao idoso, uma vez que a equipe de enfermagem desempenha inúmeras funções essenciais para garantir o cuidado integral, com qualidade e resolutividade.

Quanto à capacitação de recursos humanos na área do envelhecimento, compreende-se que esta é uma necessidade que emergiu nas últimas décadas, visto que dentre as ações governamentais propostas pela Lei $n^{\circ} 8.842$ de janeiro de 1994 , que cria a Política de Saúde do Idoso, encontra-se a inserção dos conteúdos relativos à geriatria e gerontologia nos cursos de formação de nível superior. ${ }^{8}$

Em relação à educação em saúde, sabe-se que o enfermeiro é quem geralmente coordena os serviços de educação permanente nas instituições hospitalares, função esta que é essencial, considerando que este profissional é quem mantém contanto com os membros da equipe de enfermagem. ${ }^{9}$ Além disso, dentre as funções dos profissionais da equipe de enfermagem está a responsabilidade de realizar educação em saúde destinada a pacientes e seus familiares, abordando aspectos relativos a seus problemas de saúde, autocuidado, prevenção de complicações, possibilitando, assim, a continuidade do cuidado no domicílio. A ação educativa ou a educação em saúde constitui-se em uma prática desenvolvida junto a grupos sociais, embasados em conhecimentos que compõem as áreas interdisciplinares da saúde e da educação. ${ }^{10}$

Diante deste cenário, as instituições hospitalares necessitam criar mecanismos para qualificar a assistência de enfermagem ao idoso e propor espaços para que os profissionais possam sanar dúvidas e buscar o aperfeiçoamento. Dentre esses mecanismos, encontra-se a realização de grupos de profissionais, ou seja, formação de grupos com a finalidade de discutir temas de interesse e que visem à qualificação profissional. Desse modo, com o desenvolvimento da pesquisa poderá haver contribuições para o cuidado de enfermagem ao idoso hospitalizado.

Para tanto, definiu-se como questão de pesquisa: Quais as contribuições das oficinas temáticas para o cuidado a pacientes idosos hospitalizados, desenvolvidas junto a profissionais de enfermagem? Centrado nesse problema de pesquisa, tem-se como objetivo de estudo analisar as contribuições de oficinas temáticas para o cuidado de idosos hospitalizados, desenvolvidas junto a profissionais de enfermagem.

\section{MÉTODO}

Esta pesquisa tem caráter qualitativo, descritivo e utiliza como referencial teórico-metodológico a Pesquisa Convergente-Assistencial (PCA). Este referencial permite ao pesquisador envolver os participantes da pesquisa no processo de educação em saúde e, simultaneamente, produzir dados para a investigação, empregando a reflexão e discussão em grupo. ${ }^{11}$ A PCA consiste na articulação intencional com a prática do cuidado, isto é, integrar a pesquisa na prática de enfermagem. Esse modelo de pesquisa requer a participação ativa dos sujeitos do estudo. ${ }^{11}$

Os dados foram produzidos no período de janeiro a março de 2012, por meio de entrevista semiestruturada, oficinas temáticas e observação participante. 0 local de coleta dos dados foi uma unidade de clínica médica, visto que os pacientes nela hospitalizados eram, em sua maioria, idosos. A instituição pesquisada caracteriza-se como um hospital geral, de caráter filantrópico, localizado no noroeste do Estado do Rio Grande do Sul. 


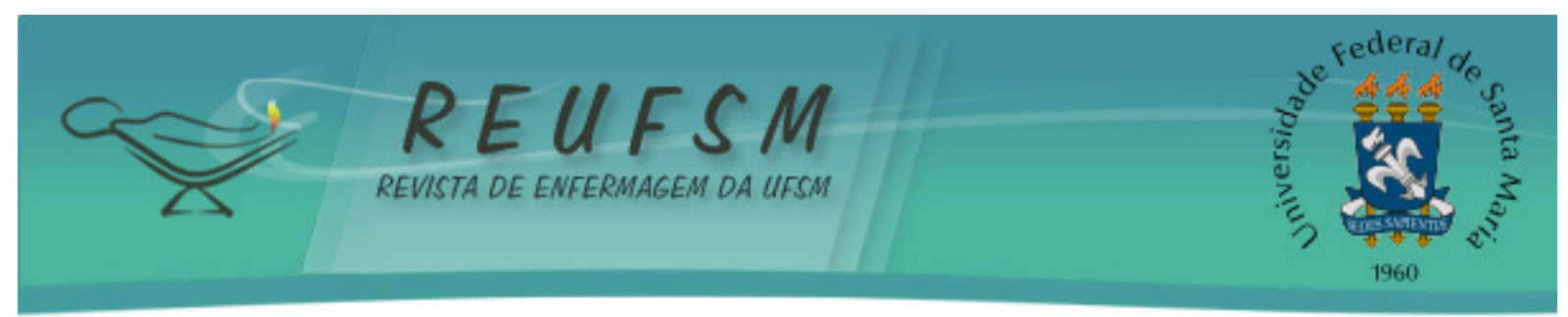

Para este estudo foram utilizados os dados relativos a duas fases da pesquisa, ou seja, os dados oriundos das oficinas temáticas, que consistem nas falas oriundas dos participantes durante as oficinas, e as falas das entrevistas. Foram realizadas quatro oficinas temáticas, sendo cada uma delas desenvolvida em dois momentos a fim de atender a um maior número de profissionais. As oficinas ocorreram em espaço próprio na instituição pesquisada, em que inicialmente foi realizada a apresentação da temática a ser discutida e, em seguida, ocorria a técnica de animação problematizadora e, na sequência, as discussões coletivas. Assim, a primeira oficina abordou conceitos relativos ao envelhecimento. Para isso, utilizou-se a dinâmica "ser idoso", em que os profissionais foram orientados a vestir-se e/ou utilizar acessórios que limitavam sua visão, sua coordenação motora e o tato. Na segunda oficina, foram abordados aspectos relativos à atenção de enfermagem ao idoso hospitalizado, com enfoque no trabalho em equipe. $\mathrm{Na}$ terceira, houve a discussão acerca da comunicação com o paciente idoso hospitalizado. Para balizar a temática, inicialmente, utilizou-se uma dinâmica sobre as informações, que constituem a comunicação. A quarta oficina tratou da legislação voltada à pessoa idosa, usando-se de uma dinâmica sobre escuta ativa.

Foram considerados critérios de inclusão no estudo ser enfermeiro, técnico ou auxiliar de enfermagem, trabalhar na unidade pesquisada e demonstrar interesse em discutir coletivamente sua experiência de cuidar de idosos hospitalizados.

Desse modo, participaram do estudo três enfermeiros e 17 técnicos de enfermagem, sendo quatro do sexo masculino e 16 do sexo feminino, com idade entre 24 a 46 anos, com formação profissional de seis meses a 15 anos e o tempo de trabalho na instituição variou de três meses a dez anos e meio. Dentre os entrevistados oito deles mencionaram que tiveram alguma disciplina que abordou aspectos relativos à atenção de enfermagem a pessoa idosa, durante sua formação profissional. Quanto à participação em cursos de atualização, dez realizaram atualizações (treinamentos) propostas pela instituição hospitalar, oito fizeram cursos ofertados por outras instituições, um não respondeu ao questionamento e um entrevistado não participou de nenhuma capacitação/atualização após sua formação.

Todos os preceitos éticos da Resolução $196 / 96^{12}$ foram respeitados e o projeto foi aprovado pelo comitê de ética em pesquisa da instituição sob número do processo 23081.016665/2011-49 e Certificado de Apresentação para Apreciação Ética (CAAE): 0340.0.243.000-11 em 20 de dezembro de 2011. Para garantir o anonimato dos sujeitos, estes foram codificados pela letra $E$ (entrevistado) mais um número, não estando na ordem da realização das entrevistas. As oficinas receberam o código Of, mais o número da oficina.

Os dados foram analisados de acordo com a Análise Temática ${ }^{13}$, sendo que as etapas seguidas foram: pré-análise, exploração e tratamento do material obtido e interpretação.

\section{RESULTADOS E DISCUSSÃO}

A partir das leituras das informações foi possível construir uma categoria temática, a qual versa sobre o espaço grupal como possibilidade de aprendizado e aperfeiçoamento.

\section{Atividade grupal como possibilidade de aprendizado e atualização}

Grupos se formam por associações com inúmeros objetivos, seja para a sobrevivência, trabalho ou afinidade. ${ }^{14}$ Assim sendo, para a realização desse estudo, utilizou-se esse artifício para discutir e desenvolver estudos acerca de temas relativos ao envelhecimento humano com os profissionais de enfermagem de uma unidade hospitalar de internação clínica. 


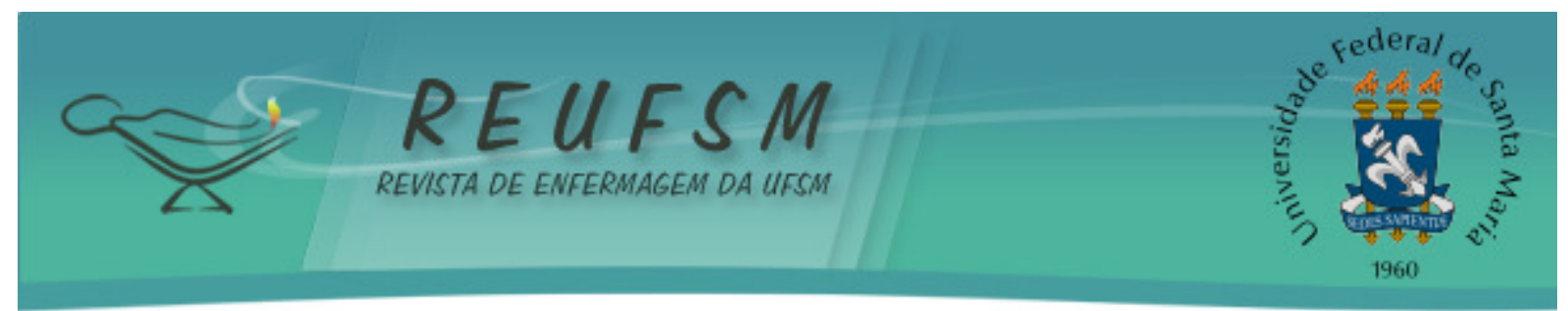

A maior parte dos sujeitos que participou das oficinas temáticas referiu que estas são importantes estratégias de qualificação da assistência e que, com a vivência das oficinas, ocorreram mudanças na forma de prestarem o cuidado ao idoso hospitalizado. Nesse aspecto, a realização de grupos, com vistas ao desenvolvimento de educação em saúde, permite a enfermagem superar o caráter curativo e alcançar a promoção a saúde. $\mathrm{E}$ assim, também, o profissional poderá ampliar sua dimensão de cuidado. ${ }^{15}$

Nesse cenário, sob a ótica dos profissionais, o desenvolvimento de ações educativas, por meio de grupos, deveria ser uma prática inerente às atividades profissionais, em quaisquer situações.

Eu acho importante. Sempre é bom relembrar quando a gente já sabe, mas às vezes a gente esquece alguns pontos. A maneira $e$ como trabalhar com a pessoa idosa. (E2)

Importante porque a gente aprende cada vez mais. É bem legal. (E5)

Outros relatos dos participantes deste estudo apontam que a realização da atividade grupal com profissionais de enfermagem que atuam em diferentes turnos de trabalho, permite que eles discutam e troquem informações relativas às condições clínicas dos pacientes, em especial dos idosos, o que comumente não ocorre, por não haver tempo ou por não terem a possibilidade de se encontrar. Além disso, a utilização de técnicas de animação grupal balizadoras e questões disparadoras de debate, o que permitiu fortalecer o diálogo acerca de determinada temática, especialmente em relação ao cuidado de enfermagem do idoso hospitalizado, favorecendo para mudanças na prática profissional.

Eu achei que foi boa a dinâmica de simular de ser uma pessoa idosa. E como a gente não tem muito acesso aos colegas do dia, houve uma oportunidade de entrar em contato com eles e ver o que acontece durante o dia, com cada paciente. Porque às vezes de noite é uma coisa e no caso o paciente idoso de noite não enxerga direito e hoje, como foi comentado, às vezes tu tens uma visão $e$ durante o dia é diferente. Foi muito bom. (E3)

Nós temos que aprender mais, tem algo sempre a aprender. Por mais que tu lidas todos os dias com o idoso, ele tem muitos anos de diferença e tem uma experiência, mas tu sempre aprendes mais, sempre tens uma prática que tu podes aprender. Gostei dessas práticas, essa última dos pássaros, adorei essa. (E6)

Pelos depoimentos pode-se constatar que o desenvolvimento de dinâmicas, com vistas a problematizar a atenção de enfermagem ao idoso hospitalizado, consiste em uma importante estratégia para a qualificação do cuidado. Isto porque, as oficinas permitiram debater acerca do envelhecimento humano, saberes e práticas do cuidar, comunicação e legislação gerontogeriátrica, entre outros aspectos.

Quanto à atenção ao idoso, a enfermagem desempenha papel fundamental, tanto na esfera da promoção da saúde e prevenção de agravos como na reabilitação do idoso, por meio de intervenções técnicas e de orientações adequadas, ou seja, da educação em saúde. Neste sentido, as atividades educativas representam um grande número de possibilidades para o aperfeiçoamento das capacidades humanas, sendo facilitadoras para as condições salutares de vida do homem e seu contexto. ${ }^{14}$ 


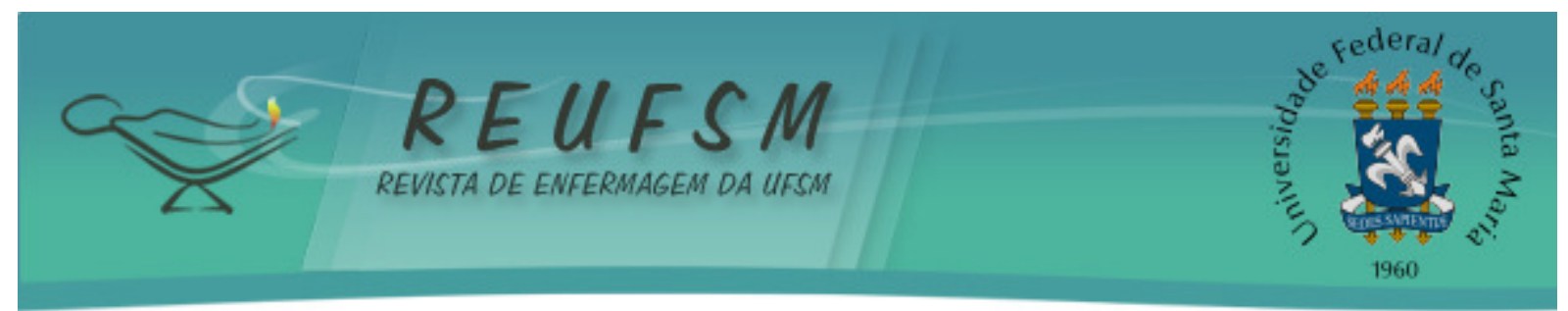

A educação permanente em todas as áreas, o que inclui a enfermagem, ultrapassa a concepção de aperfeiçoamento técnico, por proporcionar a busca da autonomia, da cidadania e a desalienação. ${ }^{16}$ Nesse cenário, a identificação das demandas da qualificação pelos trabalhadores de enfermagem, destaca a necessidade do conhecimento técnico-científico. Além disso, as ações educativas contemplam a mudança de paradigma na formação profissional e na atenção à saúde. ${ }^{17}$

Embora haja uma tendência de mudança de paradigma no que concerne ao entendimento do que seja a velhice, sabe-se que o processo de envelhecimento humano, ainda, é abordado como um conjunto de perdas físicas, mentais e sociais e que ocasiona limitações no sujeito. Contudo, é importante lembrar que velhice não é sinônimo de doença. A saúde e o bem-estar do idoso estão relacionados com a autonomia e a independência que ele possui. Destaca-se que as políticas sociais e de saúde devem priorizar ações preventivas, de manutenção da saúde, independência e autonomia do idoso. Assim, a educação em saúde visa também a preservação da capacidade funcional do idoso, mesmo diante de uma condição crônica de saúde. ${ }^{18}$

A realização de oficinas para discutir aspectos relacionados ao cuidado do idoso, caracteriza-se como ferramentas de otimização da assistência. Ainda, os profissionais participantes do estudo, ponderam que a participação nas oficinas representou um momento de grande aprendizado, de compartilhamento e de qualificação pessoal.

Valeu a pena. Foi ótimo. Cada um tem uma opinião e juntando tudo é uma grande uma coisa. Tipo, um tem uma dúvida, o outro tem outra e, no final, dá um resultado bom. (E5)

A partir do momento que você tem um estudo que aborde esse tema, você tem, em tese, aquele compromisso de discutir sobre aquele assunto e é o que traz maior conhecimento, maior prática na realidade do idoso. Por isso é interessante que tenha mais estudos sobre isso, uma vez que, por mínimo que seja a contribuição sempre traz uma contribuição a mais. (E17)

A realização da educação por meio de atividades grupais resulta em um acréscimo de conhecimento. Este fato considera que, para a proposta educativa se concretizar, tornam-se necessárias algumas reflexões críticas entre os sujeitos envolvidos, tendo em vista a avaliação processual das atividades. ${ }^{10}$ Pode-se perceber, pelos relatos, que a participação nas oficinas possibilitou a ampliação do conhecimento dos sujeitos do estudo, fato este apontado como positivo tendo-se em vista que a produção do conhecimento de forma articulada entre todos os membros da equipe representa uma conquista institucional.

Desse modo, a formação de profissionais em enfermagem se constitui em uma estratégia das políticas de saúde e de atenção à população idosa, pois contribui para a construção do conhecimento no campo do envelhecimento e direciona para uma intervenção compreensiva, centrada na pessoa que envelhece, no seu contexto e, em especial, quando necessita de cuidado. Assuntos como envelhecimento e sociedade, políticas de atenção, intervenções e cuidados gerontológicos, aspectos relativos à prevenção de morbidades e de promoção da saúde devem estar entre os conteúdos a serem desenvolvidos no decorrer do curso. ${ }^{19}$

Eu aproveitei. No caso você tratou de um monte de assuntos e tipo a gente lida no dia-a-dia, mas não para pra pensar e analisar aquilo ali, tu vens e trabalha como se fosse uma máquina, já é aquela rotina, mas tu não paras e analisas realmente, tipo, o paciente em si. (E3) 


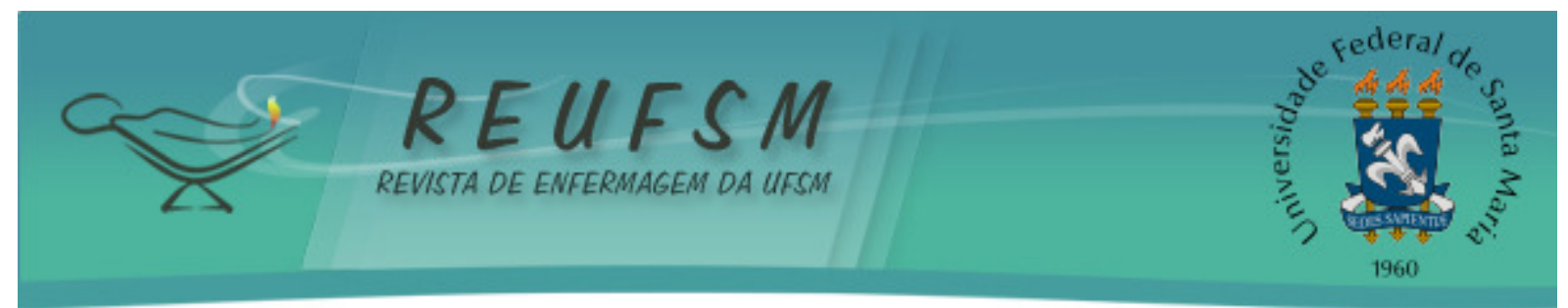

A educação consiste em um processo dinâmico e contínuo de construção do conhecimento, pelo desenvolvimento do pensamento livre e da consciência críticoreflexivo, em que as relações humanas ocasionam a consolidação de um compromisso pessoal e profissional, com vistas à promoção social. Nesta perspectiva, compreende-se que a educação em serviço para a enfermagem representa uma importante ferramenta para a assistência eficaz ao paciente. ${ }^{20}$

Os participantes consideram, também, que a realização de grupos permite a integração e harmonização da ação dos profissionais, pois todos os envolvidos agem com vistas ao cuidado do paciente.

Eu acho que o grupo fica mais unido, cada um procura fazer o melhor e o paciente fica bem melhor, todo mundo colabora. (E2)

Com relação às oficinas temáticas, além de representarem um espaço de socialização e construção do conhecimento, permitiram mudanças na forma de prestar a assistência ao idoso que vivencia a hospitalização.

Eu gostei das oficinas, bem descontraído. A gente sempre aprende um pouco mais. E eu trabalho tempo já, sempre aprende uma coisa nova. (E2)

Mudou com certeza. O grupo, eu acho que é bom pra analisar [...] porque o trabalho é diferente. (E3)

Pela manifestação, percebe-se que a equipe necessita de atualização constante, para introduzir novos conhecimentos ou para possibilitar um espaço de reflexão sobre a práxis cotidiana. 0 que deve ser destacado é que diante da realização da prática educativa há mudanças positivas na forma de realizar o cuidado ao paciente idoso, tornando o trabalho diferente.

Foi boa, bem boa, uma qualificação para cada um, a gente sempre aprende. Em especial o estatuto do idoso, que a gente não tinha tanto conhecimento. Valeu a pena. Foi ótimo. Acho que vale a pena, com certeza. (E5)

A princípio a gente fala mecanicamente, explica para todos, aham, entendeu, mas a pessoa não faz nada daquilo, então ela não entendeu?! Então às vezes a gente ensina, mas esquece que a maioria deles são pessoas muito leigas, para aquilo que estamos ensinando. (Of2)

As ações de educação no espaço de trabalho representam um desafio para os serviços de saúde, uma vez que as diretrizes com foco na saúde precisam partir das necessidades dos trabalhadores para que estas possam gerar mudanças no trabalho. ${ }^{20}$

0 desenvolvimento da educação permanente permite ao profissional qualificar a competência, o conhecimento e representa uma atualização, que se constituem componentes necessários para a sobrevivência. ${ }^{21}$ Desse modo, ela representa o questionamento da realidade, com vistas a mudar as práticas e a responsabilidade coletiva. ${ }^{16}$ Nessa mesma direção, entende-se que para superar a prática assistencial dos profissionais inseridos nos serviços de saúde, a educação permanente deve ser considerada como uma proposta pedagógica desenvolvida no espaço de trabalho, colocando-o em análise. ${ }^{22}$ 


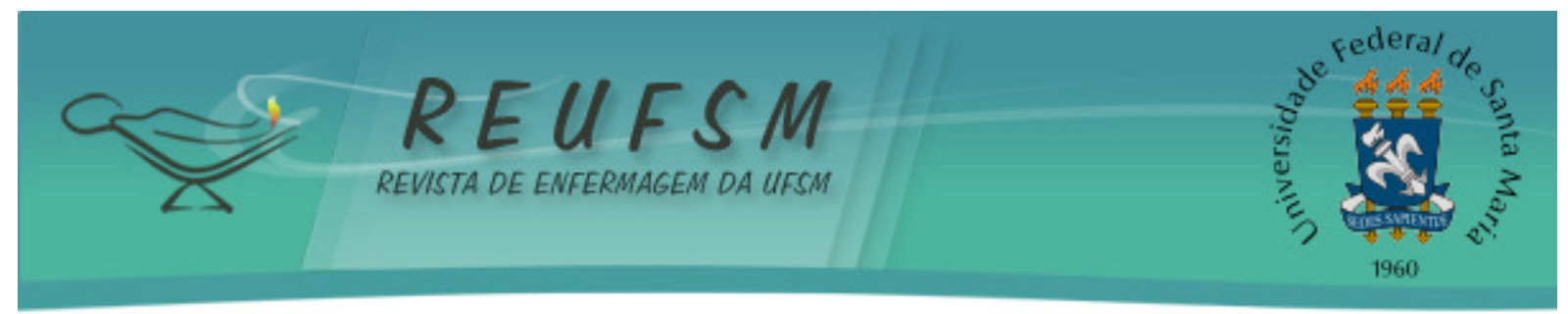

\section{CONSIDERAÇÕES FINAIS}

O estudo permitiu evidenciar a relevância da prática educativa como estratégia de intervenção e atualização da equipe de enfermagem na temática abordada. Constatou-se que há necessidade de oportunizar espaço de reflexão para os integrantes da enfermagem. Assim, a prática reflexiva favorece ampliação do conhecimento e pode provocar mudanças no exercício profissional cotidiano.

Destaca-se que o modelo adotado, por meio de oficinas temáticas, constitui-se em um modo de proporcionar aprendizado diferente do modelo tradicional da educação, o que facilita a adesão dos profissionais. Assim, busca-se incentivar os integrantes da equipe de enfermagem para modificar e aceitar as mudanças em suas práticas e concepções de educação, sensibilizando-os para uma reflexão crítica sobre sua própria formação e direcionando-os para novas aprendizagens na área da saúde.

\section{REFERÊNCIAS}

1. Comerlato BEM, Guimarães I, Alves ED. Tempo de plantar e tempo de colher: as representações sociais de profissionais de saúde e idosos sobre o processo de envelhecimento. Rev Eletrônica Enferm [Internet]. 2007 [acesso em 2013 jun 12];9(3):73647. Disponível em: http://www.fen.ufg.br/fen_revista/v9/n3/v9n3a13.htm.

2. Brasil. Lei $\mathrm{N}^{\circ} 10.741$, de $1^{\circ}$ de outubro de 2003. Dispõe sobre o Estatuto do Idoso [Internet]. [acesso em 2013 maio 23]. Disponível em: http://www.planalto.gov.br/ccivil_03/leis/2003//10.741.htm.

3. Garcia MAA, Yagi GH, Souza CS, Odoni APC, Frigério RM, Merlin SS. Atenção à saúde em grupos sob a perspectiva dos idosos. Rev Latinoam Enferm. 2006 mar/abr;14(2):175-82.

4. Cardoso MC, Marquesan FM, Lindôso ZCL, Schneider R, Gomes I, Carli GA. Análise da capacidade funcional dos idosos de Porto Alegre e sua associação com auto percepção de saúde. Estud Interdiscipl Envelhec. 2012;17(1):111-24.

5. Schimidt TCG, Silva MJP. Reconhecimento dos aspectos tacêsicos para o cuidado afetivo e de qualidade ao idoso hospitalizado. Rev Esc Enferm USP. 2013 abr;47(2):426-32.

6. Sousa RM, Santana RF, Santo FHE, Almeida JG, Alves LAF. Diagnósticos de enfermagem identificados em idosos hospitalizados: associação com as síndromes geriátricas. Esc Anna Nery Rev Enferm. 2010 out/dez;14(4):732-41.

7. Almeida ABA, Aguiar MGG. A dimensão ética do cuidado de enfermagem ao idoso hospitalizado na perspectiva de enfermeiros. Rev Eletrônica Enferm [Internet]. 2011 jan/mar [acesso em 2013 abr 10];13(1):42-9. Disponível em: http://www.revistas.ufg.br/index.php/fen/article/view/9462.

8. Brasil. Lei $\mathrm{n}^{\circ}$ 8.842, de janeiro de 1994 [Internet]. Dispõe sobre a Política Nacional do Idoso. [acesso em 2013 abr 10]. Disponível em: http://www.planalto.gov.br/ccivil_03/leis/l8842.htm.

9. Silva GM, Seiffert OMLB. Educação continuada em enfermagem: uma proposta metodológica. Rev Bras Enferm. 2009 maio/jun;62(3):362-6.

10. Acioli S. A prática educativa como expressão do cuidado em Saúde Pública. Rev Bras Enferm. 2008 jan-fev;61(1):117-21. 


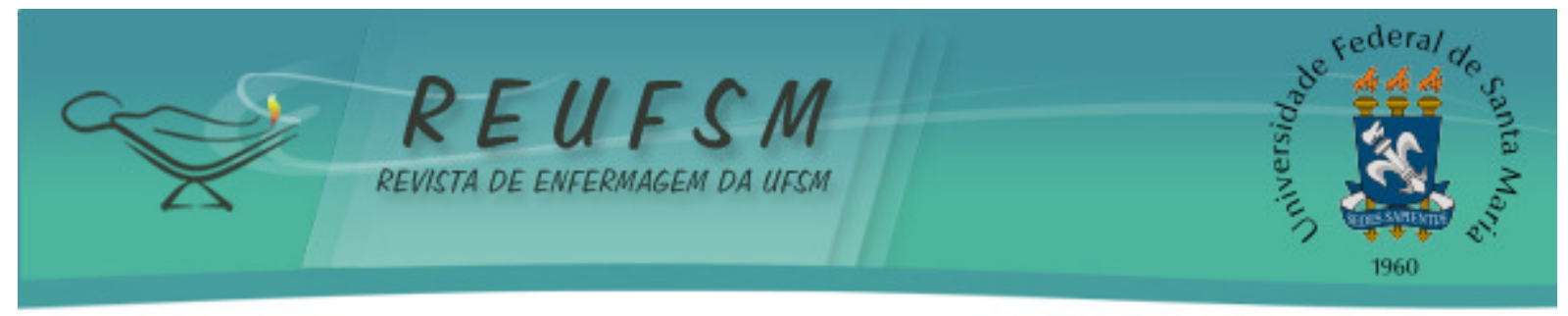

11. Trentini M, Paim L. Pesquisa Convergente Assistencial: um desenho que une o fazer e o pensar na prática assistencial em saúde-enfermagem. 2ª ed rev e ampl. Florianópolis (SC): Insular; 2004.

12. Brasil. Conselho Nacional de Saúde. Resolução CNS n 196, de 10 de outubro de 1996 [Internet]. [acesso $2013 \mathrm{dez}$ 10] Disponível em: conselho.saude.gov.br/docs/Reso196.doc.

13. Minayo MCS. O desafio do conhecimento: pesquisa qualitativa em saúde. 12a ed. São Paulo: Hucitec; 2010.

14. Vaghetti HH, Padilha MICS, Carraro TE, Pires DEP, Santos VEP. Grupos sociais e o cuidado na trajetória humana. Rev Enferm UERJ. 2007 abr/jun;15(2):267-75.

15. Gastaldi AB, Polak YNS. Grupos de convivência como estratégia no cuidado do cardiopata. Ciênc Cuid Saúde [Internet]. 2012 [acesso em 2013 abr 10];11(Supl):226-34. Disponível em: http://periodicos.uem.br/ojs/index.php/CiencCuidSaude/article/view/17080.

16. Silva LAA, Ferraz F, Lino MM, Backes VMS, Schmidt SMS. Educação permanente em saúde e no trabalho de enfermagem: perspectiva de uma práxis transformadora. Rev Gaúch Enferm. 2010 set;31(3):557-61.

17. Jesus MCP, Figueiredo MAG, Santos SMR, Amaral AMM, Rocha LO, Thiollent MJM. Educação permanente em enfermagem em um hospital universitário. Rev Esc Enferm USP. 2011 out;45(5):1229-36.

18. Veras RP. Estratégias para o enfrentamento das doenças crônicas: um modelo em que todos ganham. Rev Bras Geriatr Gerontol. 2011;14(4):779-86.

19. Leite MT, Gonçalves LHT, Battisti IDE, Hildebrandt LM. Recursos humanos de enfermagem: formação e atualização na área do envelhecimento. Rev RENE. 2011 $\mathrm{jan} / \mathrm{mar} ; 12(1): 24-32$.

20. Silva LAA, Bonacina DM, Andrade A, Oliveira TC. Desafios na construção de um projeto de educação permanente em saúde. Rev Enferm UFSM [Internet]. $2012 \mathrm{set} /$ dez [acesso em 2013 abr 10];2(3):496-506. Disponível em: http://cascavel.ufsm.br/revistas/ojs2.2.2/index.php/reufsm/article/view/5364/pdf.

21. Paschoal AS, Mantovani MF, Méier MJ. Percepção da educação permanente, continuada e em serviço para enfermeiros de um hospital de ensino. Rev Esc Enferm USP. 2007 set;41(3):478-84.

22. Lima JVC, Turini B, Carvalho BG, Nunes EFPA, Lepre RL, Mainardes P, et al. A educação permanente em saúde como estratégia pedagógica de transformação das práticas: possibilidades e limites. Trab Educ Saúde. 2010 jul/out;8(2):207-27.

Data de recebimento: $16 / 10 / 2013$

Data de aceite: $31 / 01 / 2014$

Contato com autor responsável: Marinês Tambara Leite

Endereço postal: Rua Floriano Peixoto, 776 - Centro

98700-000 - ljui/RS

E-mail: tambaraleite@yahoo.com.br 